\title{
HUBUNGAN ASUPAN ZAT BESI, VITAMIN C, DAN KEBIASAAN SARAPAN TERHADAP KONSENTRASI BELAJAR DI SMA TAMAN MADYA 5
}

\author{
Relationship Of Iron Substance, Vitamin C, And Breakfast Habits Against \\ Learning Concentration In Sma Taman Madya 5
}

\author{
Annisa Famila ${ }^{1}$, Isti Istianah ${ }^{2}$ \\ Program Studi Gizi, Fakultas Kesehatan Masyarakat, Universitas Binawan \\ Email korespondensi : istianah7@gmail.com
}

\begin{abstract}
Concentration is an ability to focus the mind. Lack of iron intake is one of the causes of anemia which will reduce the concentration of learning, Vitamin c also plays a role in helping the process of absorption of iron.Breakfast is also important to improve concentration because it is the best energy supply for the brain to concentrate. This study aims to determine how the relationship between iron intake, vitamin $\mathrm{C}$ and breakfast habits on learning concentration in Taman Madya High School 5. This study uses a cross sectional design. The sample consisted of 36 10th and 11th grade students taken by purposive sampling technique in February 2020. Data collection was carried out by conducting concentration tests using picture completion, surveying consumption of iron and vitamin c intake with the SFFQ method and interviewing breakfast habits using a questionnaire. Data were analyzed using chi-square test. The results showed there was no correlation between iron intake and learning concentration with a p-value of 0.370 , there was no correlation between vitamin $\mathrm{c}$ intake and learning concentration with a p-value of 1,000 and there was a relationship between breakfast habits and learning concentration with a p-value of 0.003 .
\end{abstract}

Keywords: iron intake, vitamin c intake, breakfast habits, learning concentration.

\begin{abstract}
ABSTRAK
Konsentrasi merupakan suatu kemampuan untuk memfokuskan pikiran. Kekurangan asupan zat besi merupakan salah satu penyebab anemia yang akan berdampak mernurunnya konsentrasi belajar, vitamin $\mathrm{C}$ juga berperan untuk membantu proses penyerapan zat besi. Sarapan pagi juga merupakan hal yang penting untuk meningkatkan konsentrasi karena merupakan pasokan energi untuk otak yang paling baik untuk berkonsentrasi. Penelitian ini bertujuan untuk mengetahui bagaimana hubungan antara asupan zat besi, vitamin $\mathrm{C}$ dan kebiasaan sarapan terhadap konsentrasi siswa yang belajar di SMA Taman Madya 5. Penelitian ini menggunakan desain cross sectional. Sampel berjumlah 36 siswi kelas 10 dan 11 yang diambil dengan teknik purposive sampling pada bulan Februari 2020. Pengumpulan data dilakukan dengan melakukan tes konsentrasi menggunakan picture completion, melakukan survei konsumsi asupan zat besi dan vitamin C dengan metode $S F F Q$ dan wawancara kebiasaan sarapan menggunakan kuesioner. Data dianalisis dengan menggunakan uji chi-square. Hasil penelitian menunjukkan ada hubungan kebiasaan sarapan terhadap konsentrasi belajar dengan nilai $p$-value 0,003 , tetapi tidak ada hubungan asupan zat besi terhadap konsentrasi belajar dengan nilai $p$-value 0,370; demikian pula asupan vitamin c juga tidak ada hubungan terhadap konsentrasi belajar dengan nilai $p$-value 1,000.
\end{abstract}

Kata kunci: asupan zat besi, asupan vitamin c, kebiasaan sarapan, konsentrasi belajar. 
J.Gipas, November 2020, Volume 4 Nomor 2 ISSN 2599-0152 eISSN 2599-2465 http://jos.unsoed.ac.id/index.php/jgps

\section{PENDAHULUAN}

Konsentrasi merupakan suatu kemampuan untuk memfokuskan pikiran, perasaan, kemauan dan segenap panca indra ke satu obyek di dalam satu aktivitas tertentu, dengan disertai usaha untuk tidak mempedulikan obyek-obyek lain yang tidak ada hubungannya dengan aktivitas tersebut. Apabila mereka tidak bisa konsentrasi dengan baik pada materi yang disampaikan, maka bisa dipastikan bahwa siswa tersebut akan menjumpai kesulitan dalam memahami pelajaran dan akan berdampak pada prestasi belajar (Hakim, 2011).

Dumilah, Sumarmi menyatakan bahwa salah satu penyebab menurunnya kemampuan dan konsentrasi belajar pada remaja adalah masalah anemia pada remaja putri. Kadar $\mathrm{Hb}$ yang tinggi dapat menunjukkan skor kecerdasan intelektual yang tinggi (Kusmiyati et al, 2013).

Anemia merupakan masalah kurang gizi mikro yang cukup besar di dunia dengan prevalensi 40\% (WHO 2015). Perkiraan perbandingan anemia di negara berkembang dan negara maju untuk anak usia sekolah 53\% dan 9\%. Rekomendasi WHO pada World Health Assembly (WHA) ke-65 menyepakati rencana aksi dan target global untuk gizi ibu ,bayi dan anak dengan komitmen mengurangi separuh (50\%) prevalensi anemia pada WUS untuk tahuh 2025 (WHO, 2016).

Hasil Riskesdas tahun 2013, prevalensi anemia di Indonesia adalah 21,7\%; prevalansi anemia lebih banyak terjadi pada perempuan yaitu sebesar $23,9 \%$, dan prevalensi kejadian anemia pada usia 1524 tahun sebesar 18,4\%. Angka ini lebih tinggi apabila dibandingkan dengan kelompok umur 25-34 tahun. Hasil studi evaluasi program penanggulangan anemia pada tahun 2000-2004 di Kabupaten Safe Motherhood Project A partnership and Family Approach (SMP-FA) oleh IAKMI ditemukan bahwa prevalensi anemia pada WUS untuk kelompok remaja 23,6\%. Keadaan kesehatan dan gizi kelompok usia 10-24 tahun di Indonesia masih memprihatinkan. Data Survei Kesehatan Rumah Tangga (SKRT) tahun 2012 menyatakan bahwa prevalensi anemia pada balita sebesar 40,5\%, ibu hamil sebesar $50,5 \%$, ibu nifas sebesar $45,1 \%$, remaja putri usia 10-18 tahun sebesar 57,1\% dan usia 1945 tahun sebesar 39,5\%. Wanita mempunyai risiko terkena anemia paling tinggi terutama pada remaja putri (Kemenkes RI, 2013). 
J.Gipas, November 2020, Volume 4 Nomor 2

ISSN 2599-0152 eISSN 2599-2465 http://jos.unsoed.ac.id/index.php/jgps

Hasil penelitian dari Anggraini 2010, menunjukkan bahwa prevalensi anemia gizi pada remaja putri di 5 wilayah Jakarta adalah 44,6 \%. Berdasarkan survei pendahuluan yang di lakukan pada bulan September di SMA Taman Madya 5 menunjukan bahwa prevalensi anemia pada siswi di SMA Taman Madya 5 adalah 42,8\%.

Anemia pada remaja dapat menyebabkan keterlambatan pertumbuhan fisik, gangguan perilaku serta emosional. Hal ini dapat mempengaruhi proses pertumbuhan dan perkembangan sel otak sehingga dapat menimbulkan daya tahan tubuh menurun, mudah lemas dan lapar, konsentrasi belajar terganggu (Sayogo, 2006).

Menurut Briawan (2014), tingginya kejadian anemia pada remaja disebabkan oleh beberapa faktor diantaranya rendahnya asupan zat besi dan zat gizi lainnya seperti vitamin A, C, folat, riboplafin dan B12. Vitamin $\mathrm{C}$ dapat meningkatkan absorpsi besi dalam bentuk nonheme hingga empat kali lipat, yaitu dengan merubah feri menjadi fero dalam usus halus sehingga mudah untuk diabsorpsi. Salah satu upaya dalam mengatasi kadar hemoglobin rendah yaitu dengan mengkonsumsi makanan yang mengandung vitamin $\mathrm{C}$ untuk membantu penyerapan besi (Lewa, 2016).
Remaja putri memiliki resiko sepuluh kali lebih besar untuk menderita anemia dibandingkan dengan remaja putra, hal ini terjadi karena setiap bulan remaja putri mengalami menstruasi yang menyebabkan pengeluaran zat besi meningkat dan berdampak pada kurangnya zat besi dalam darah, (Tarwoto et al, 2010). Kecukupan asupan zat besi pada saat remaja sangat penting untuk agar tidak terjadi anemia pada remaja, jika anemia pada remaja putri tidak diatasi, akan berdampak pada anak menjadi stunting. Selain itu juga dapat mengganggu pertumbuhan yang menyebabkan anak menjadi gizi kurang dan meningkatkan risiko diare dan infeksi saluran nafas (Syaugi dan Istianah, 2019). Kekurangan zat besi juga berpengaruh pada ibu hamil, yang dapat mengganggu pertumbuhan yang menyebabkan anak menjadi gizi kurang dan meningkatkan risiko diare dan infeksi saluran nafas

Selain asupan zat besi dan vitamin C yang menjadi salah satu faktor tingginya kejadian anemia yang akan berdampak pada menurunnya konsentrasi belajar, sarapan pagi juga merupakan hal yang penting untuk meningkatkan konsentrasi belajar karena sarapan pagi merupakan pasokan energi untuk otak yang paling baik agar dapat 
J.Gipas, November 2020, Volume 4 Nomor 2 ISSN 2599-0152 eISSN 2599-2465 http://jos.unsoed.ac.id/index.php/jgps

berkonsentrasi di sekolah. Ketika bangun pagi, gula darah dalam tubuh rendah karena semalaman tidak makan. Sudah banyak penelitian membuktikan bahwa sarapan teratur membuat anak lebih berprestasi di sekolah daripada anak yang tidak sarapan. Sarapan memperbaiki kemampuan memecahkan masalah, daya ingat, konsentrasi, persepsi visual dan berfikri kreatif menurut Dr. Joanne Lunn, ahli gizi senior dari British Nutrition Fondation (Khomsan, 2010).

Di Indonesia $18,05 \%$ anak tidak sarapan pagi (Sufrin, 2018). Menurut Rikesdas 2010, mutu sarapan penduduk Indonesia masih rendah karena masih banyak anak yang tidak terbiasa melakukan sarapan sehat. Penduduk yang mengkonsumsi energi di bawah kebutuhan minimal lebih rendah dari 70\% Angka Kecukupan Gizi (AKG) bagi orang Indonesia tahun (2004) adalah sebanyak 40,6\%. Proporsi defisit energi terbanyak pada anak usia sekolah (41,2\%), remaja $(54,5 \%)$ dan ibu hamil $(44,2 \%)$.

Anak yang tidak biasa sarapan pagi, mudah lelah dan tidak kuat melakukan aktifitas, tidak mampu berpikir dan berkonsentrasi serta tidak dapat berpartisipasi penuh dalam belajar (Sufrin 2018). Sejalan dengan penelitian yang di lakukan oleh
Safaryani et al. (2017) dan Lentini (2014) yang menyatakan bahwa kebiasaan sarapan mempengaruhi tingkat konsentrasi belajar.

Dari uraian diatas, maka peneliti tertarik untuk melakukan penelitian mengenai hubungan asupan zat besi, vitamin C dan kebiasaan sarapan terhadap konsentrasi belajar siswi di SMA Taman Madya 5. Penelitian ini bertujuan untuk mengetahui hubungan asupan zat besi, vitamin $\mathrm{C}$ dan kebiasaan sarapan terhadap konsentrasi belajar siswi di SMA Taman Madya 5.

\section{METODE}

Penelitian ini menggunakan desain penelitian Cross Sectional dengan jenis penelitian kuantitatif. dimana variabel terikat dan variabel bebas diukur pada saat yang bersamaan. Variable terikat yaitu konsentrasi belajar dan variabel bebas yaitu asupan zat besi, asupan vitamin $\mathrm{C}$ dan kebiasaan sarapan. Alasan pemilihan desain Cross Sectional karena variabel independen dan variabel dependen diteliti dalam satu waktu. Penelitian dilaksanakan pada siswi di SMA Taman Madya 5 Kelurahan Rawasari, Kecamatan Cempaka Putih, Jakarta Pusat. Adapun pelaksanaannya dilakukan pada bulan Februari tahun 2020. Penelitian ini 
J.Gipas, November 2020, Volume 4 Nomor 2

ISSN 2599-0152 eISSN 2599-2465 http://jos.unsoed.ac.id/index.php/jgps

telah mendapat persetujuan etik dari Komisi Etik Universitas Pembangunan Nasional "Veteran" Jakarta dengan nomor B/2339/1/2020/KEPK.

Populasi yang digunakan dalam penelitian ini adalah seluruh siswi kelas $X$ dan XI di SMA Taman Madya 5 Kelurahan Rawasari, Kecamatan Cempaka Putih, Jakarta Pusat. Sampel penelitian berjumlah 36 siswi yang diperoleh dengan teknik purposive sampling. Adapun kriteria inklusi dan eksklusi sebagai berikut:

Kriteria inklusi adalah:

1. Sampel adalah siswi kelas X dan XI di SMA Taman Madya.

2. Tidak dalam keadaan sakit (demam, pusing dan sakit kepala).

Sebagai kriteria eksklusi adalah: Siswi yang tidak mengikuti penelitian secara menyeluruh. Jumlah sampel yang dibutuhkan dalam penelitan ini dihitung dengan menggunakan rumus Solvin:

$$
\begin{aligned}
& \mathrm{n}=\frac{\mathrm{N}}{1+\mathrm{N}(\mathrm{d})^{2}} \\
& \mathrm{n}=\frac{39}{1+39(0.05)^{2}} \\
& \mathrm{n}=\frac{39}{1+39(0.0025)} \\
& \mathrm{n}=\frac{39}{1.097}
\end{aligned}
$$

$$
\mathrm{n}=35.5 \text { Orang }=36 \text { Orang }
$$

Untuk antisipasi drop out maka di tambah $10 \%$ dari sampel sehingga jumlah sampel menjadi 39 sampel.

Pengumpulan data untuk konsentrasi belajar sampel diperoleh dari hasil pengukuran konsentrasi dengan menggunakan teknik Picture Completion. Teknis pelaksanaannya yaitu sampel dibagi menjadi dua grup dalam kelas yang berbeda lalu mengerjakan soal Picture Completion (melengkapi gambar yang hilang) sebanyak 15 soal selama 7,5 menit.

Data asupan zat besi dan vitamin c diperoleh dari wawancara survei konsumsi dengan metode SFFQ (Semiquantitative Food Frequency Questionare) kepada sampel agar memberitahukan bahan makanan yang dikonsumsi sampel selama satu bulan terakhir, khususnya bahan makanan yang mengandung zat besi dan vitamin c beserta frekuensinya dalam sehari, seminggu atau sebulan dan besar porsinya setiap kali makan. Data kebiasaan sarapan diperoleh dengan cara melakukan wawancara kepada sampel dan memberikan kuesioner kebiasaan sarapan.

Data yang dikumpulkan dilakukan pemeriksaan terlebih dahulu (editing data), 
J.Gipas, November 2020, Volume 4 Nomor 2 ISSN 2599-0152 eISSN 2599-2465 http://jos.unsoed.ac.id/index.php/jgps

lalu coding data pada variabel dengan jenis kategori, yaitu variabel asupan zat besi, asupan vitamin c, kebiasaan sarapan dan konsentrasi belajar. Kemudian proses entry data. Untuk data asupan zat besi dan vitamin c di entry ke nutrisurvey terlebih dahulu untuk mengetahui jumlah asupan zat besi dan vitamin c selanjutnya di bandingkan dengan kebutuhan sesuai dengan AKG. Setelah itu semua variabel di entry ke Microsoft Excel dengan cara memasukkan kode responden, skor hasil jawaban dari pertanyaan pada kuesioner. Lalu proses cleaning data yang bertujuan untuk meminimalisir kesalahan seperti kesalahan pengkodean atau data kurang lengkap serta mencegah adanya missing data pada saat uji analisis bivariate. Analisis data meliputi analisis univariat dan bivariat. Analisis univariat berupa gambaran distribusi frekuensi variabel, sedangkan analisis bivariat berupa hubungan antara variabel dependen dan independen menggunakan uji chi-square.

\section{HASIL DAN PEMBAHASAN}

\section{Analisis Univariat}

Tabel 1 menunjukkan bahwa uang saku siswi di SMA Taman Madya 5 sebesar $\leq$ Rp. 20.000 adalah 86,1 \% (21 responden) dan sebesar >Rp. 20.000 adalah 13,9 \% (5 responden). Dari hasil wawancara yang dilakukan uang saku paling kecil adalah sebesar RP.10.000 dan paling besar Rp. 30.000. Rata- rata uang saku siswi di SMA Taman Madya adalah sebesar Rp.20.000.

Tabel 1. Distribusi Frekuensi Karakteristik Responden Berdasarkan Uang Saku di SMA Taman Madya 5

\begin{tabular}{lcc}
\hline Uang Saku & $\mathrm{N}$ & $\%$ \\
\hline SRp. 20.000 & 31 & $86,1 \%$ \\
>Rp. 20.000 & 5 & $13,9 \%$ \\
Jumlah & $\mathbf{3 6}$ & $\mathbf{1 0 0 \%}$ \\
\hline
\end{tabular}

Tabel 2 menunjukkan bahwa 19,4\% (7 responden) memiliki asupan zat besi yang baik. Sedangkan $80,6 \%$ (29 responden) memiliki asupan zat besi yang kurang. Asupan zat besi tertinggi responden adalah 26,3 $\mathrm{mg} /$ hari dan asupan zat besi terkecil adalah 2,1 $\mathrm{mg} /$ hari. Sedangkan rata-rata asupan zat besi responden adalah 9,7 mg/hari.

Tabel 2. Distribusi Frekuensi Asupan Zat Besi di SMA Taman Madya 5 Asupan Zat Besi Frekuensi Persentase

\begin{tabular}{ccc}
\hline & $(\mathbf{n = 3 6})$ & $\mathbf{( \% )}$ \\
\hline Baik & 7 & 19.4 \\
Kurang & 29 & 80.6 \\
Jumlah & $\mathbf{3 6}$ & $\mathbf{1 0 0} \%$ \\
\hline
\end{tabular}

Responden dengan nilai asupan zat besi tertinggi yaitu $26,3 \mathrm{mg} /$ hari diketahui ratarata konsumsi bahan makanan sumber zat besi heme berupa daging ayam $2 \mathrm{x} / \mathrm{ming} g \mathrm{u}$ sebanyak $55 \mathrm{~g}$, daging sapi 1 x/bulan 
J.Gipas, November 2020, Volume 4 Nomor 2 ISSN 2599-0152 eISSN 2599-2465 http://jos.unsoed.ac.id/index.php/jgps

sebanyak $35 \mathrm{~g}$, hati ayam 4x/minggu sebanyak $30 \mathrm{~g}$, telur $2 \mathrm{x} /$ hari sebanyak 2 butir atau $110 \mathrm{~g}$, ikan tongkol dan ikan kembung 1x/minggu, masing-masing sebanyak $40 \mathrm{~g}$, ikan asin 3x/minggu sebanyak $15 \mathrm{~g}$, ikan teri kering 2x/minggu sebanyak $15 \mathrm{~g}$, udang 1x/minggu sebanyak $35 \mathrm{~g}$, susu $2 \mathrm{x} / \mathrm{hari}$ sebanyak $200 \mathrm{cc}$. sedangkan aspan sumber zat besi non heme yaitu kacang tanah dan kacang hijaulx/minggu masing-masing sebanyak 20 gram, oncom 1x/minggu sebanyak 20 gr, tempe $2 \mathrm{x} /$ hari sebanyak $50 \mathrm{~g}$, bayam 5x/minggu sebnayak $100 \mathrm{~g}$, sawi 4x/minggu sebanyak $100 \mathrm{~g}$, daun singkong dan kangkung $100 \mathrm{~g} / \mathrm{hari}$, tomat 3x/minggu sebanyak $50 \mathrm{~g}$, salak 2x/bulan sebnayak $65 \mathrm{~g}$, jeruk 2x/bulan sebanyal $110 \mathrm{~g}$, pepaya 1x/minggu sebanyak 110 g. Selain itu konsumsi tablet tambah darah rutin $1 \mathrm{x} /$ minggu yang menyumbangkan zat besi sebanyak $8 \mathrm{mg} / \mathrm{hr}$.

Pada responden dengan nilai asupan zat besi terkecil yaitu $2,1 \mathrm{mg} /$ hari diketahui ratarata konsumsi bahan makanan sumber zat besi heme berupa daging ayam, ikan, telur ayam 3x/buan sebnayak $50 \mathrm{~g}$, dengan frekuensi 2-3x/bulan, hati ayam 2x/minggu sebanyak 30 g, daging sapi $1 \mathrm{x} / \mathrm{bulan}$ sebanyak 35 g,kerang 1x/minggu, keju 1x/bulan sebanyak $35 \mathrm{~g}$, sedengkan supan zat besi non heme berupa kacang hijaudan oncom 3x/minggu masing-masing sebnayak $20 \mathrm{~g}$,tempe 1x/hr sebanyak $50 \mathrm{~g}$, kangkong dan sawi 2x/bulan sebnayak $100 \mathrm{~g}$, salak,jeruk dan pepaya $2 x /$ bulan sebanyak 50 g. Responden juga tidak meminum tablet tambah darah dengan rutin. Rata-rata asupan zat besi responden adalah 9,7 mg/hari tidak mencapai angka kecukupan gizi zat besi yang dianjurkan yaitu $\geq 15 \mathrm{mg} / \mathrm{hr}$. Hal ini disebabkan rendahnya jumlah asupan zat besi yang dikonsumsi baik hem maupun non heme serta tidak rutinnya responden minum tablet tambah darah sesuai anjuran yaitu 1x/minggu. Dari 36 responden, terdapat 11 responden $(30,5 \%)$ yang rutin mengkonsumsi tablet tambah darah 1x/minggu.

Tabel 3 menunjukkan bahwa 47,2\% (17 responden) memiliki asupan vitamin $\mathrm{C}$ yang baik. Sedangkan 52,8\% (19 responden) memiliki asupan vitamin $\mathrm{C}$ yang kurang. Asupan vitamin c tertinggi responden adalah $176,9 \mathrm{mg} /$ hari dan asupan vitamin $\mathrm{c}$ terkecil adalah 12,5 $\mathrm{mg} /$ hari. Sedangkan rata-rata asupan vitamin c responden adalah 29,7 $\mathrm{mg} /$ hari.

Tabel 3. Distribusi Frekuensi Asupan Vitamin C di SMA Taman Madya 5

\begin{tabular}{ccc}
\hline Asupan Vitamin C & $\begin{array}{c}\text { Frekuensi } \\
(\mathbf{n = 3 6})\end{array}$ & $\begin{array}{c}\text { Persentase } \\
(\mathbf{\%})\end{array}$ \\
\hline Baik & 17 & 47.2 \\
Kurang & 19 & 52.8 \\
\hline
\end{tabular}


J.Gipas, November 2020, Volume 4 Nomor 2 ISSN 2599-0152 eISSN 2599-2465 http://jos.unsoed.ac.id/index.php/jgps

Jumlah 36 $100 \%$

Responden dengan nilai asupan vitamin c tertinggi yaitu $176,9 \mathrm{mg} /$ hari diketahui ratarata konsumsi bahan makanan sumber vitamin $\mathrm{c}$ berupa jambu biji $2 \mathrm{x} / \mathrm{bulan}$ sebanyak $100 \mathrm{~g}$, jeruk 4x/minggu sebanyak 50 gr, sari jeruk 1x/minggu sebanyak $100 \mathrm{ml}$, mangga 2x/minggu sebanyak 90 g, mangga muda 2x/minggu sebanyak $50 \mathrm{~g}$, pepaya 2x/minggu sebanyak $110 \mathrm{~g}$, pisang ambon 2x/bulan sebanyak $50 \mathrm{~g}$, strawberry 1x/minggu sebanyak $50 \mathrm{~g}$, daun singkong 2x/hari sebanyak 100 g, kembang kol 2x/minggu sebanyak 100 g, salada air 1x/minggu sebanyak $50 \mathrm{~g}$, tauge $3 \mathrm{x} /$ bulan sebanyak 100 g,wortel 3x/minggu sebanyak $100 \mathrm{~g}$, singkong 1x/minggu sebanyak $100 \mathrm{~g}$ dan suplemen vitamin c (vitasimin) 2x/bulan sebanyak 1 tablet yang menyumbangkan vitamin c sebanyak 33,3 mg/hr. Responden dengan nilai asupan vitamin c terkecil yaitu 12,5 mg/hari diketahui frekuensi asupan vitamin c berupa buah-buahan dan sayuran jarang di konsumsi, rata-rata konsumsi bahan makanan sumber vitamin c berupa lemon $2 \mathrm{x} /$ bulan sebanyak $100 \mathrm{~g}$, mangga $1 \mathrm{x} /$ minggu sebanyak $90 \mathrm{~g}$, tauge 1x/bulan sebanyak $25 \mathrm{~g}$ dan tidak mengkonsumsi suplemen vitamin $\mathrm{c}$ untuk tambahan.
Rata - rata asupan vitamin c responden adalah 29,7 mg/hari tidak mencapai angka kecukupan gizi vitmin c yang dianjurkan yaitu $\geq 75 \mathrm{mg} / \mathrm{hr}$. Hal ini disebabkan rendahnya konsumsi asupan sayur dan buah sebagai sumber vitamin c secara rutin baik dari variasi dan frekuensi mkanannya. Dari 36 responden terdapat 17 responden (47\%) rutin mengkonsumsi suplemen vitamin $\mathrm{C}$ seperti vitasimin, you c 1000 dan lemon water dengan frekuensi 1-3x/minggu.

Tabel 4 menunjukkan bahwa 69,5\% (25 responden) memiliki kebiasaan makan yang baik, sedangkan 30,5\% (11 responden) memiliki kebiasaan sarapan pagi yang kurang baik. Skor tertinggi dari kuesioner kebiasaan sarapan adalah 20 , skor terkecil adalah 9 dan rata-rata skor adalah 16. 69,5\% responden yang memiliki kebiasaaan makan yang baik adalah responden yang memiliki kebiasaan sarapan sebelum jam 09.00 WIB dengan menu makanan lengkap yaitu karbohidrat dan lauk pauk, sedangkan 30,5\% responden memiliki kebiasaan makanan yang kurang adalah responden yang memiliki kebiasaan makan pagi > jam 09.00 WIB dengan menu kue ringan atau minuman ringan.

Tabel 4. Distribusi Frekuensi Kebiasaan Sarapan di SMA Taman Madya 5

\section{Kebiasaan Sarapan Frekuensi Persentase}


J.Gipas, November 2020, Volume 4 Nomor 2 ISSN 2599-0152 eISSN 2599-2465 http://jos.unsoed.ac.id/index.php/jgps

\begin{tabular}{ccc} 
& $(\mathbf{n = 3 6})$ & $(\boldsymbol{\%})$ \\
\hline Baik & 25 & 69.5 \\
Kurang & 11 & 30.5 \\
\hline Jumlah & $\mathbf{3 6}$ & $\mathbf{1 0 0} \%$ \\
\hline
\end{tabular}

Tabel 5 menunjukkan bahwa 72,2\% (26 responden) memiliki tingkat konsentrasi belajar yang baik, sedangkan 27,8\% (10 responden) memiliki tingkat konsentrasi belajar yang kurang baik. Skor terendah tes konsentrasi pada penelitian ini adalah 8 sebanyak 3 responden dan Skor tertinggi adalah 15 sebanyak 1 responden. Berikut adalah tabel distribusi frekuensi jawaban responden berdasarkan soal konsentasi belajar di SMA Taman Madya 5. dari 15 soal konsentrasi belajar, terdapat 3 soal dimana responden menjawab benar semua (100\%), yaitu pada soal 1, 3 dan 4 . Hal ini terjadi karena soal tersebut berada pada nomor awal yang berdekatan dengan soal gambar yang hampir mirip sehingga responden mudah untuk menjawabnya. Sedangkan pada soal 2 sebanyak 61\% (22 responden) menjawab salah, hal ini karena soal pada nomor 2 adalah membedakan gambar bergaris dimana kedua gambar sulit untuk dibedakan.

Tabel 5. Distribusi Frekuensi Konsentrasi Belajar di SMA Taman Madya 5

\begin{tabular}{ccc}
\hline Kebiasaan Sarapan & $\begin{array}{c}\text { Frekuensi } \\
(\mathbf{n = 3 6})\end{array}$ & $\begin{array}{c}\text { Persentase } \\
(\boldsymbol{\%})\end{array}$ \\
\hline Baik & 26 & 72.2 \\
Kurang & 10 & 27.8 \\
Jumlah & $\mathbf{3 6}$ & $\mathbf{1 0 0} \%$ \\
\hline
\end{tabular}

\section{Analisis Bivariat}

Analisis bivariat pada Tabel 6 menunjukkan hasil analisis hubungan dari 3 variabel yaitu, hubungan asupan zat besi terhadap konsentrasi belajar, hubungan vitamin c terhadap konsentrasi belajar dan hubungan kebiasaan sarapan terhadap konsentrasi belajar.

Tabel 6. Hasil Analisis antara Variabel Independen dengan Variabel Dependen

\begin{tabular}{|c|c|c|c|c|c|c|c|}
\hline \multirow{3}{*}{ Variabel } & \multicolumn{4}{|c|}{ Tingkat Konsentrasi } & \multirow{2}{*}{\multicolumn{2}{|c|}{ Total }} & \multirow{3}{*}{$p$ value } \\
\hline & \multicolumn{2}{|c|}{ Baik } & \multicolumn{2}{|c|}{ Kurang } & & & \\
\hline & $\mathbf{N}$ & $\%$ & $\mathbf{N}$ & $\%$ & $\mathbf{N}$ & $\%$ & \\
\hline \multicolumn{8}{|l|}{ Asupan Zat Besi } \\
\hline Baik & 4 & 57.1 & 3 & 42.9 & 7 & 19.5 & \multirow{2}{*}{0.370} \\
\hline Kurang & 22 & 75.9 & 7 & 24.1 & 29 & 80.5 & \\
\hline \multicolumn{8}{|l|}{ Asupan Vitamin $C$} \\
\hline Baik & 12 & 70.6 & 5 & 29.4 & 17 & 47.2 & \multirow{2}{*}{1.000} \\
\hline Kurang & 14 & 73.7 & 5 & 26.3 & 19 & 52.8 & \\
\hline \multicolumn{8}{|l|}{ Kebiasaan Sarapan } \\
\hline Baik & 22 & 88.0 & 3 & 12.0 & 25 & 69.4 & \\
\hline Kurang & 4 & 36.4 & 7 & 63.6 & 11 & 30.6 & 0.003 \\
\hline
\end{tabular}


J.Gipas, November 2020, Volume 4 Nomor 2

ISSN 2599-0152 eISSN 2599-2465

http://jos.unsoed.ac.id/index.php/jgps

Hasil analisis hubungan kebiasaan sarapaan terhadap konsentrasi belajar dapat diketahui bahwa responden yang memiliki konsentrasi belajar yang baik dan juga mempunyai kebiasaan sarapan yang baik terdapat 22 responden $(88,0 \%)$ lebih besar dibandingkan dengan responden yang memiliki konsentrasi belajar yang kurang dan juga memiliki kebiasaan sarapan yang kurang sebanyak 7 responden $(63,6 \%)$. Dari hasil wawancara diketahui bahwa dari 11 responden dengan kebiasaan sarapan yang kurang terdapat 5 responden $(45,4 \%)$ menyatakan suka sakit perut dan buang air besar jika melakukan kebiasaan sarapan pagi,dan sisa nya $(63,6 \%)$ menyatakan malas dan kesiangan, sehinga responden lebih memilih untuk makan pada saat jam istirahat. Hasil uji chi square antara kebisaan sarapan terhadap konsentrasi belajar didapatkan bahwa nilai $p$ value 0,003 $(\mathrm{p}<0,05)$ yang artinya ada hubungan antara kebiasaan sarapan terhadap konsentrasi belajar. Hal ini menunjukkan bahwa semakin baik kebiasaan sarapan maka semakin baik pula konsentrasi belajarnya. Sarapan pagi merupakan sumber glukosa yang baik. Glukosa merupakan sumber energi utama untuk kerja otak yang mana dapat mempengaruhi konsentrasi belajar.
Hasil penelitian ini sesuai dengan beberapa penelitian sebelumnya tentang hubungan kebiasaan sarapan pagi dengan konsentrasi. Penelitian yang di lakukan oleh Surfrin (2018) yang dilakukan di SDN Baruga Kota Kendari yang menyatakan ada hubungan yang bermakna antara kebiasaan sarapan dengan konsentrasi belajar dengan nilai $(\mathrm{p}<0,05)$, sama dengan hasil

penelitian Mahmudiono dan Wardoyo (2013), yang dilakukan di SDN Wonocatur dan SDN Sumbarejo 1 Kabupaten Kediri menyatakan ada hubungan yang bermakna antara kebiasaan sarapan dengan konsentrasi belajar dengan nilai p 0,003 .

Penelitian ini juga sesuai dengan penelitian yang dilakukan oleh Lentini dan Margawati (2014), di SMK Batik 2 Surakarta yang menyatakan bahwa terdapat hubungan yang signifikan antara kebiasan sarapan dengan konsentrasi berfikir dengan nilai $\mathrm{p}=$ 0,000 . Peneliti menyatakan, anak yang tidak terbiasa sarapan akan berdampak pada kemampuan konsentrasi ketika mengerjakan tugas di kelas. Perilaku belajar anak salah satunya merupakan dampak positif dari sarapan. Anak yang terbiasa sarapan akan menjadi lebih bersemangat belajar, 
J.Gipas, November 2020, Volume 4 Nomor 2 ISSN 2599-0152 eISSN 2599-2465 http://jos.unsoed.ac.id/index.php/jgps

konsentrasi dan daya ingat meningkat serta kondisi emosional anak cenderung baik.

Penelitian yang dilakukan oleh Winata (2015), kepada mahasiswa tahun ketiga PSIK UMY juga yang menyatakan terdapat hubungan yang signifikan antara kebiasan sarapan dengan konsentrasi belajar nilai $p$ value $0,014(\mathrm{p}<0,05)$.

Hasil penelitian ini juga sesuai dengan teori yang ada bahwa sarapan pagi merupakan pasokan energi untuk otak yang paling baik agar dapat berkonsentrasi di sekolah.

Rifameuti dalam Tamsuri (2010), juga menyatakan bahwa dipagi hari kegiatan anak memerlukan energi untuk dan berinteraksi dengan lingkungannya. Dengan sarapan anak menjadi lebih bersemangat dan aktif dalam belajar. Melewatkan sarapan pagi menyebabkan tubuh kekurangan glukosa dan hal ini menyebabkan tubuh lemah dan kurang konsentrasi karena tiadanya suplai energi (Khomsan, 2010).

Pada hasil analisis hubungan asupan zat besi terhadap konsentrasi belajar diketahui bahwa responden yang memiliki konsentrasi belajar yang baik ternyata memiliki asupan zat besi yang kurang sebanyak 75,9\% (22 responden), sedangkan responden yang memiliki konsentrasi belajar yang kurang tetapi mempunyai asupan zat besi yang baik sebanyak 42,9\% (3 responden). Hasil uji chi square antara asupan zat besi terhadap konsentrasi belajar didapatkan bahwa nilai $p$ value $0,370(\mathrm{p}>0,05)$ yang artinya tidak terdapat hubungan antara asupan zat besi terhadap konsentrasi belajar.

Hasil penelitian ini berbeda dengan hasil penelitian yang dilakukan oleh Rahayu, (2013) yang dilakukan di SMAN 2 Cimahi menyatakan ada hubungan yang signifikan antara asupan zat besi dengan konsentrasi belajar dengan nilai $p$ value $0,000(\mathrm{p}<0,05)$. Hal ini disebabkan karena konsentrasi belajar tidak hanya dipengaruhi oleh asupan zat besi saja tetapi juga ada faktor-faktor lainnya. Menurut Desiawan, A (2015), Asupan zat besi bukan merupakan satu-satunya faktor yang berpengaruh terhadap konsentrasi dan prestasi belajar siswa. Konsentrasi belajar juga dipengaruhi oleh faktor - faktor lain yaitu kemampuan visual motorik panca indera, lingkungan sekolah, sikap, motivasi dan IQ. Tingkat kecerdasan sangat menentukan berhasil atau tidaknya seorang siswa dalam belajar (Suryabrata, 2008). Hakim (2011) juga menyatakan bahwa konsentrasi belajar tidak hanya di pengaruhi oleh nutrisi/zat gizi saja yang termasuk faktor internal. Namun demikian, konsentrasi juga 
J.Gipas, November 2020, Volume 4 Nomor 2

ISSN 2599-0152 eISSN 2599-2465

http://jos.unsoed.ac.id/index.php/jgps

banyak dipengaruhi oleh berbagai faktor eksternal, antara lain suara, pencahayaan, temperatur serta desain belajar yang memiliki pengaruh sebagai media atau sarana dalam belajar, seperti halnya terdapat seseorang yang senang belajar di tempat santai sambil duduk di kursi, sofa, tempat tidur maupun di karpet. Cara tersebut merupakan salah satu cara yang dapat membuat seseorang lebih dapat berkonsentrasi.

Hasil analisis hubungan asupan vitamin c terhadap konsentrasi belajar diketahui bahwa responden yang memiliki konsentrasi belajar yang baik ternyata memiliki asupan vitamin c yang kurang sebanyak 73,7\% (14 responden), sedangkan responden yang memiliki konsentrasi belajar yang kurang tetapi mempunyai asupan vitamin c yang baik sebanyak 29,4\% (5 responden). Hasil uji chi square antara asupan zat vitamin c terhadap konsentrasi belajar didapatkan bahwa nilai $p$ value $1,000(\mathrm{p}>0,05)$ yang artinya tidak terdapat hubungan antara asupan vitamin c terhadap konsentrasi belajar.

Pada penelitian ini dapat di lihat bahwa siswi yang memiliki asupan vitamin c yang kurang, lebih besar daripada sisiwi yang memiliki asupan vitamin c yang baik, sejalan dengan hasil asupan zat besi pada siswi di SMA Taman Madya 5, dimana siswi dengan asupan zat besi yang kurang juga lebih besar dari pada sisiwi yang memiliki asupan zat besi yang baik. Salwen (2011), menyatakan bahwa salah satu fungsi vitamin c membantu penyerapan zat besi, sehingga jika terjadi kekurangan vitamin c, maka jumlah zat besi yang diserap akan berkurang dan bisa terjadi anemia yang dapat berpengaruh pada konsentrasi belajar. vitamin c berperan dalam absorbsi dan pelepasan zat besi dari transferin ke jaringan. Vitamin $\mathrm{C}$ berperan dalam pemindahan zat besi dari transferin di dalam plasma ke feritin hati (Almatsier, 2009). Vitamin C dapat mereduksi zat besi feri menjadi fero di dalam usus halus sehingga mudah untuk diabsorpsi. Absorpsi zat besi dalam bentuk heme dapat meningkat empat kali lipat bila bercampur dengan vitamin $\mathrm{C}$. Kekurangan vitamin $\mathrm{C}$ dapat menyebabkan turunnya daya tahan tubuh, kontraksi otot melemah sehingga dapat menyebabkan kelelahan. Adapun ciri-ciri yang tampak akibat dari kekurangan vitamin $\mathrm{C}$, yaitu penampilan fisik yang terlihat tidak segar (William, 2005). Menurut Nurlintang (2018), Kondisi kekurangan Vitamin $\mathrm{C}$ baik dalam asupan maupun didalam darah tidak berpengaruh terhadap fungsi kognitif .

\section{KESIMPULAN DAN SARAN}


J.Gipas, November 2020, Volume 4 Nomor 2

ISSN 2599-0152 eISSN 2599-2465

http://jos.unsoed.ac.id/index.php/jgps

Sampel pada penelitian ini berjumlah 36

orang dengan rata- rata uang saku sebesar $\leq$ Rp. 20.000 sebanyak 21 orang dengan persentase 86,1\% dan sebesar >Rp. 20.000 sebanyak 5 orang dengan persentase 13,9\%. Sampel yang memiliki asupan zat besi yang baik sebanyak 19,4\% dan yang kurang $80,6 \%$, sampel yang memiliki asupan vitamin c yang baik sebanyaka $47,2 \%$ dan yang kurang 52,8\%, sampel yang memiliki kebiasaan sarapan yang baik sebanyak 69,5 $\%$ dan yang kurang 30,5 \%, sampel yang memiliki konsentrasi belajar yang baik sebanyak 72,2 \%dan yang kurang sebanyak $27,8 \%$

Tidak ada hubungan antara asupan zat besi, vitamin $\mathrm{c}$ terhadap konsentrasi belajar dan ada hubungan yang signifikan antara kebiasaan sarapan dengan konsentrasi belajar.

Perlu dilakukan penelitian lebih lanjut dengan cakupan yang lebih luas seperti metode yang beragam untuk mengetahui lebih jauh hubungan antara asupan zat besi, vitamin c dan kebiasaan sarapan terhadap konsentrasi belajar serta faktor-faktor lain yang mempengaruhinya. Perlu adanya penyuluhan dan edukasi lebih lanjut kepada siswi mengenai pentingnya memenuhi asupan gizi dan kebiasaan sarapan pagi.

\section{DAFTAR PUSTAKA}

Almatsier S. 2009. Prinsip Dasar Ilmu Gizi. Jakarta: PT. Gramedia Pustaka Utama.

Anggraeni, A. 2010. Faktor-Faktor Yang Berhubungan Dengan Status Anemia Gizi Besi Pada Siswi SMU Di Wilayah Dki Jakarta. Jakarta: BKPI-LIPI.

AKG. 2019. PMK No 28 Angka Kecukupan Gizi yang Dianjurkan bagi Bagsa Indonesia. Menteri Kesehatan RI, Jakarta.

Briawan, D. 2014. Anemia Masalah Gizi Pada Remaja Wanita. Jakarta : EGC.

Desiawan, Arga. 2015. Hubungan Asupan Zat Besi (Fe) dan Status Gizi dengan Prestasi Belajr Siswa Sekolah Dasar di SDN Kudu 02 Kecamatan Baki Kabupaten Sukoharjo. [SKIPSI] Fakultas Ilmu Kesehatan Univrsutas Muhammadiyah Surakarta: Surakarta

Dumilah et al. 2017. Hubungan Anemia dengan Prestasi Belajar Siswi di SMP Unggul Bina Insani. Jornal Unair. Volume 1 (No 4): 331-340.

Hakim, T. 2011. Belajar Secara efektif.Jakarta: Pustaka Pembangunan Swadaya Nusantara.

Syaugi M, Istianah I. 2019. Hubungan Asupan Zat Besi (FE), Riwayat MPASI dengan Status Gizi BB/U pada Balita Usia 12-59 Bulan. Binawan Student Journal. Vol. 1, No. 3.

Kementrian Kesehatan Republik Indonesia. 2013. Jakarta : Kemenkes RI.

Khomsan,Ali, 2010. Gizi Anak Sekolah. Jakarta : PT Raja Grafindo Persada.

Kusmiyati Y, Meilani N, Ismail S. 2018 Kadar hemoglobin dan kecerdasan intelektual anak. Jurnal Kesehatan Masyarakat. Vol. 3, No. 1 : 115118.

Lentini, B dan Margawati, A. 2014. Hubungan Kebiasaan Sarapan Dan Status Hidrasi Dengan Konsentrasi Berfikir Pada Remaja. Jurnal of Nutrition College. Vol. 3, No. 4 : 631-437

Lewa, A. 2016. Hubungan asupan protein, zat besi dan vitamin $c$ dengan kejadian anemia pada remaja putri di MAN 2 Model Palu. Jurnal Publikasi Kesehatan Masyarakat Indonesia.Vol. 3, No. 1. 
J.Gipas, November 2020, Volume 4 Nomor 2

ISSN 2599-0152 eISSN 2599-2465

http://jos.unsoed.ac.id/index.php/jgps

Mahmudiono, T dan Wardoyo, A. 2013. Hubungan Makan Pagi dan Tingkat Konsumsi Zat Gizi dengan Daya Konsentrasi Siswa Sekolah Dasar. Media Gizi Indonesia. Vol. 9, No. 1 : 49-53

Nurlintang, Amar. 2018. Kecukupan asupan Fe dan vitamin C pada kejadian kurang gizi anak balita di desa joho Kecamatan Mojolaban Kabupaten Sukoharjo. [SKRIPSI] Fakultas Ilmu Kesehatan UMS : Surakarta.

Profil Kesehatan Indonesia, 2012. Jakarta : Kemenkes RI

Rahayu, Kory. 2013. Hubungan antara asupan zat besi dan kadar hemoglobin terhadap konsentrasi siswa di SMAN 2 Cimahi. [KTI]. Poltekkes Kemenkes Bandung: Bandung.

Riset Kesehatan Dasar. 2013. Badan Penelitian dan Pengembangan Kesehatan Departemen Kesehatan. Jakarta:Departemen Kesehatan Republik Indonesia.

Safaryani et al. 2017. Pengaruh Sarapan Pagi Terhadap Tingkat Konsentrasi Belajar Anak SDN Karangayu 02 Semarang. [Skripsi]. POLTEKKES Kendari: Kendari.

Salwen, MJ. 2011. Vitamins and trace elements. In: McPherson RA, Pincus MR, eds.Salwen MJ. Vitamins and trace elements. In: McPherson RA, Pincus MR, eds. Henry's Clinical Diagnosis and Management by Laboratory Methods. 22nd ed. Philadelphia, PA: Elsevier Saunders; : Chap 26.

Sayogo, S. 2006. Gizi Remaja Putri. Jakarta : EGC

Sufrin F. 2018. Hubungan Sarapan Pagi dengan Konsentrasi Belajar Anak SD negeri 01 Baruga di Kota Kendari.

[Skripsi]. STIKES Telogorejo Semarang: Semarang.

Suryabrata, S. 2008. Psikologi Pendidikan. Yogyakarta: Rajawali Pers.

Tarwoto, A. R, Nuraeni, A., Mirawiyana, B., Tauchid, S. N., Aminah, S., Sumiati., Dinarti., Nurhaeni, H., Saprudin, A. E dan Chairani, R/ Tarwoto et al. 2010. Kesehatan remaja Problem dan Solusinya. Poltekkes Depkes Jakarta I : Salemba Medika.

WHO. Global nutrition targets 2025: anemia policy brief (WHO/NMH/NHD/14.4). Geneva : World Health Organization2014. (http://apps.who.int/iris/bitstream/handle/10665/1 48556/WHO_NMH_NHD_14.4_eng.pdf?sequenc $\mathrm{e}=1$, di akses 8 Oktober 2019, jam 15.40 WIB ).
WHO. Nutritional Anaemias: Tools For Effective Preventive And Control. Geneva: World Healt Organization 2017. (http://apps.who.int/iris/bitstream/handle/10665/2 59425/9789241513067_eng.pdf?sequence $=1$, di akses 8 Oktober 2019, jam 15.40 WIB).

Winata, HY. 2015. Hubungan Perilaku Sarapan dengan Konsentrasi Belajar Mahasiswa Tahun Ketiga Program Studi Ilmu Keperawatan. [Skripsi]. Fakultas Kedokteran dan Ilmu Kesehatan. UMY : Yogyakarta. 